\title{
Study of carotid disease in patients with peripheral artery disease
}

\section{Estudo da doença carotídea em pacientes com doença arterial periférica}

\author{
Leonardo Ghizoni Bez ; ; Túlio Pinho Navarro²
}

A B S T R A C T

\begin{abstract}
Objective: To study the stenosis of the carotid arteries in patients with symptomatic peripheral arterial disease. Methods: we assessed 100 consecutive patients with symptomatic peripheral arterial disease in stages of intermittent claudication, rest pain or ulceration. Carotid stenosis was studied by echo-color-doppler, and considered significant when greater than or equal to $50 \%$. We used univariate analysis to select potential predictors of carotid stenosis, later taken to multivariate analysis. Results: The prevalence of carotid stenosis was $84 \%$, being significant in $40 \%$ and severe in $17 \%$. The age range was $43-89$ years (mean 69.78). Regarding gender, $61 \%$ were male and $39 \%$ female. Half of the patients had claudication and half had critical ischemia. Regarding risk factors, $86 \%$ of patients had hypertension, $66 \%$ exposure to smoke, $47 \%$ diabetes, $65 \%$ dyslipidemia, $24 \%$ coronary artery disease, $16 \%$ renal failure and $60 \%$ had family history of cardiovascular disease. In seven patients, there was a history of ischemic cerebrovascular symptoms in the carotid territory. The presence of cerebrovascular symptoms was statistically significant in influencing the degree of stenosis in the carotid arteries ( $p=0.02$ at overall assessment and $p=0.05$ in the subgroups of significant and non-significant stenoses). Conclusion: the study of the carotid arteries by duplex scan examination is of paramount importance in the evaluation of patients with symptomatic peripheral arterial disease, and should be systematically conducted in the study of such patients.
\end{abstract}

Key words: Carotid arteries. Carotid stenosis. Peripheral arterial disease. Risk factors.

\section{INTRODUCTION}

Adirec ther therosclerosis is the disease of the modern world, directly related to lifestyle, such as physical inactivity, smoking, stress and diet. As a systemic disease, it affects many arteries simultaneously, such as coronary, carotid and lower limb arteries.

It is important to study the whole patient, evaluating the various arterial vessels 1 . Therefore, the diagnosis of atherosclerosis in patients still in the early or subclinical stages enables earlier and more appropriate treatment and prevents possible complications ${ }^{2}$.

Complications of atherosclerosis, such as acute myocardial infarction and stroke, are now among the leading causes of morbidity and mortality worldwide. The stroke is now the leading cause of death in Brazil ${ }^{3-5}$.

Peripheral artery disease is responsible for 42,000 cases of amputation per year in Brazil in accordance with the 2005-2011 Data/SUS ${ }^{6}$. It is associated with the same risk factors of coronary artery disease and carotid artery stenosis.

Peripheral artery disease is an important marker of atherosclerosis and is also a predictor of cardiac and cerebrovascular events. Patients with peripheral artery disease have a higher chance of morbidity and mortality from ischemic heart and cerebrovascular diseases, such as acute myocardial infarction and stroke. These patients have a mortality of approximately $30 \%$ in five years and $50 \%$ in ten years ${ }^{7}$, and have a higher incidence of atherosclerosis in the carotid territory ${ }^{8}$. Some studies have estimated that approximately $25 \%$ to $35 \%$ of these patients show significant stenosis in the carotid arteries ${ }^{9}$. The identification of these patients has the potential to prevent stroke, since it may establish the correct medical or surgical treatment.

About $15 \%$ to $48 \%$ of strokes are caused by atherosclerosis of the carotid arteries ${ }^{10}$. The treatment of stroke has low success rates, with $30 \%$ of patients who remain hospitalized for long periods and 30\% requiring permanent care in the long term.

The incidence of stroke could be reduced by up to $50 \%$ with the modification and control of risk factors such as smoking, diabetes, hyperlipidemia, hypertension, among others. Identifying patients with stenosis of the carotid arteries would allow early clinically or surgical treatment (endarterectomy or angioplasty) ${ }^{11}$.

1. Post-Graduation Program in Applied Sciences for Surgery and Ophthalmology, Faculty of Medicine, Universidade Federal de Minas Gerais;

2. Department of Surgery, Faculty of Medicine, Universidade Federal de Minas Gerais. 
The diagnosis of significant carotid disease can be made by ultrasound with color-Doppler, called "duplex scan", which is a non-invasive and inexpensive test. Prospective, randomized studies have shown the benefits of treatment of carotid stenosis in reducing the incidence of cerebral ischemia, both in symptomatic and in asymptomatic patients 12-17.

The aim of this study was to study the stenosis of the carotid arteries in patients with symptomatic peripheral arterial disease, assessing the prevalence of carotid artery disease, the severity of peripheral arterial disease, the severity of involvement of extracranial carotid arteries and the associated risk factors.

\section{METHODS}

We prospectively evaluated 100 patients with symptomatic peripheral arterial disease treated in the Governador Felicio Rocho and Israel Pinheiro (IPSEMG) hospitals from June 2011 to April 2012.

The study was approved by the Ethics Committee of the Felicio Rocho Hospital in May 2011, and recorded with the protocol number 365/2011, and also approved by the Ethics Committee of the Universidade Federal de Minas Gerais (CAAE 403541112.2.0000.5149). Patients were invited to participate in the study and enrolled after signing the Informed Consent Form (ICF).

After the diagnosis of carotid stenosis, all patients received clinical treatment with antiplatelet agents, statins and control of risk factors and associated diseases.

We consecutively included in the study patients with symptomatic peripheral arterial disease in stages of intermittent claudication (rank 1, 2 or 3 of Rutherford), rest pain (Rutherford classification 4) or ulceration (Rutherford 5 or 6). We excluded patients who disagreed to participate and those at risk of imminent death or severe systemic disease.

The evaluation of carotid stenosis was performed by eco-color-doppler. Significant stenosis of the carotid arteries was defined as equal to or greater than $50 \%$. The carotid arteries were examined bilaterally, the stenosis degree being considered the one on the side with more pronounced involvement. To measure the degree of stenosis, we used the consensus document that correlates criteria of flow speed and anatomical data ${ }^{18}$.

For evaluation of peripheral arterial disease, patients underwent anamnesis and physical examination, with assessment of various risk factors for atherosclerosis, measurement of ankle-brachial index (ABI) and Rutherford classification.

The risk factors assessed were age, gender, smoking, diabetes, dyslipidemia, hypertension, medications used to control hypertension, coronary artery disease, renal failure, family history of atherosclerosis, previous history of lower limb revascularization, myocardial revascularization
, aortic aneurysm, intervention in the carotid arteries, renal artery intervention, amputation, history of ischemic cerebrovascular symptoms related to the carotid artery territory and arterial territory affected in lower limb (aortoiliac, femoropopliteal or infrapopliteal). The presence of some motor limitation regarding ambulation was evaluated and deemed reduced in patients using wheelchairs or restricted to bed. We considered patients symptomatic as for the carotid territory those with a history of focal neurological symptoms directly related to this territory, such as amaurosis fugax, hemiparesis or hemiplegia.

For $A B I$ measurement, we used a sphygmomanometer with $10-12 \mathrm{~cm}$ wide cuff positioned just above the ankle and measured systolic pressure with portable doppler in posterior tibial and fibular dorsalis pedis arteries. The $A B I$ is obtained by the ratio of the highest systolic pressure in the arteries at the ankle level and the highest systolic pressure in the brachial artery (left or right).

This study is characterized as a cros-sectional, prospective epidemiological one. We used univariate analysis to select potential predictors of severity of carotid artery stenosis by evaluating: the degree of carotid artery stenosis on a scale ranging from $0 \%$ (no stenosis) to $100 \%$ (occlusion), not accounting for the subgroups of stenosis degrees. For these calculations we employed the MannWhitney test and Spearman coefficient, used to evaluate the influence of $\mathrm{ABI}$ and classification of clinical severity (Rutherford classification).

We used the chi-square and Mann-Whitney tests and, where necessary, the Chi-Square was replaced by Fisher's exact test to assess carotid stenosis. Patients were separated into two subgroups of stenosis degrees, one less than 50\% (not significant stenosis) and another above 50\% (significant stenosis). To select among the potential predictors in multiple regression, we used the backward algorithm. For the evaluation of the carotid treated in its original scale, without subdivision into groups of grades of stenosis, we employed the method of Quasi-Likelihood. We used logistic regression for the carotid evaluation in subgroups.

Since the objective of the study was to test the correlation between carotid stenosis and peripheral artery disease, and given a significance level of 0.05 for a twotailed test with a medium effect size and a power of $80 \%$, the sample should be composed of approximately 85 individuals (Figure 1).

\section{RESULTS}

The age of patients ranged from 43 to 89 years, with a mean of 69.78 (standard deviation 10.01). Sixtyone patients were male. Nineteen patients had reduced motor activity. The distribution of patients according to the degree of stenosis of the carotid arteries is found in Table 1. 
The prevalence of carotid stenosis was $84 \%$, being significant in $40 \%$ of patients and severe in $17 \%$. Absence of plaque in the carotid arteries was found in $16 \%$. Two patients had unilateral internal carotid occlusion; one had a history of stroke two years before and the other was asymptomatic.

Regarding the classification of Rutherford, $50 \%$ of patients had grades 1,2 or 3 (claudicating) and $50 \%$ of patients had grades 4, 5 or 6 (patients with rest pain or ulceration, i.e., critical ischemia). The $\mathrm{ABI}$ measurement showed an average of 0.58 , with $50 \%$ of the patients with less than 0.56 .

We note that $86 \%$ of the patients had hypertension, $66 \%$ exposure to smoke, $47 \%$ diabetes, $65 \%$ dyslipidemia, $24 \%$ coronary artery disease, $16 \%$ renal failure and $60 \%$ had family history of cardiovascular disease (Table 2). A history of vascular surgery was found in $48 \%$ of the patients, with a predominance of lower limb revascularization, performed in 34 patients (34\%), and coronary artery bypass grafting (CABG) in ten (10\%).

Seven patients (7\%) had a history of some prior ischemic cerebrovascular symptoms in the carotid territory,

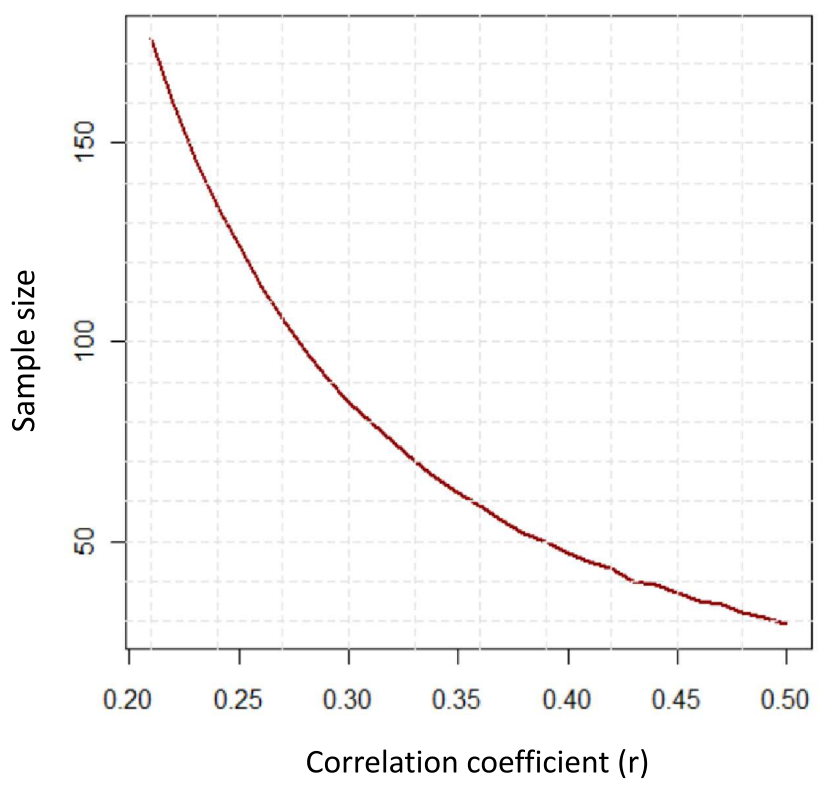

Figure 1 - Curve of sample and effect sizes, fixing $80 \%$ power and a significance level of $5 \%$ for the correlation coefficient $(r=0.30)$. two of them (2\%) TIA and five patients (5\%) stroke. In all these patients, this story had occurred more than two years before.

Patients were classified according to the arterial territory affecting the lower limbs, with findings of femoropopliteal disease in $63 \%$, Infrapopliteal in $43 \%$ and aortoiliac in $26 \%$.

After the diagnosis of carotid stenosis we evaluated the approach to to this finding. In $76 \%$ of patients observation was chosen, and $24 \%$ held some additional procedure. Of the latter, 15 were submitted only to more exams (new duplex-scan, angiography or magnetic resonance angiography) and nine patients underwent intervention in the carotid arteries, of which three were carotid endarterectomies and six were carotid angioplasties. All patients undergoing carotid endarterectomy or angioplasty had carotid stenosis higher or equal to $70 \%$ (severe stenosis). These patients had no complications postoperatively. Variables that significantly influenced the degree of stenosis of the carotid arteries showed a pd" 0.25 , being selected for multivariate analysis: prior symptomatic cerebrovascular disease, dyslipidemia, reduced motor activity, age, coronary artery disease, renal failure (Table 3).

There was a negative correlation, although not significant ( $p=0.073$ ) between the $A B I$ and the overall evaluation of carotid stenosis. The correlation between the assessment of carotid and the classification of Rutherford, on its turn, is positive, but also not significant ( $p=0.110$ ) (Figure 2).

The following variables were selected as potential predictors of significant carotid stenosis ( $p d^{\prime \prime} 0.25$ ): reduced motor activity, history of previous symptomatic cerebrovascular disease, gender, age, diabetes, dyslipidemia and coronary artery disease (Table 4).

In multivariate analysis with the previously selected variables, only the variable previous symptomatic cerebrovascular disease remained in the final regression to globally explain the variation of carotid stenosis. The presence of prior symptomatic cerebrovascular disease increases in 30.98 the average value of carotid stenosis, with $p=0.0231$

In the assessment of carotid stenosis in groups of significant injuries and non-significant ones, only the variables prior symptomatic cerebrovascular disease and gender were retained in the final regression to explain the

Table 1 - Distribution of patients according to the degree of carotid artery stenosis.

\section{Degree of carotid Stenosis}

Absence of plaques

Less than $50 \%$ stenosis

$50-69 \%$ stenosis

$70-99 \%$ stenosis

Occlusion
Number of patients

$16(16 \%)$

$44(44 \%)$

$23(23 \%)$

$15(15 \%)$

$2(2 \%)$ 
Table 2 - Distribution of the number of patients about the risk factors and associated diseases

\begin{tabular}{lcc}
\hline Variables & No & Yes \\
\cline { 2 - 3 } & AF & AF \\
\hline Hypertension & 14 & 86 \\
Exposure to smoke & 34 & 66 \\
Diabetes & 53 & 47 \\
Dyslipidemia & 35 & 65 \\
Coronary disease & 76 & 24 \\
Renal insufficiency & 84 & 16 \\
Family history of atherosclerosis & 40 & 60 \\
Prior history of vascular surgery & 52 & 48 \\
Previous cerebrovascular disease: asymptomatic & 7 & 93 \\
Amputation & 97 & 3 \\
\hline
\end{tabular}

AF: absolute frequency

variation in evaluation of carotid stenosis. The results show that the chance of a female patient have an assessment of significant carotid stenosis is 2.28 (0.92 to 5.68) times the odds of male patients, but not statistically significant $(p=$ 0.0766). The odds of a patient with prior symptomatic cerebrovascular disease present with a carotid stenosis considered significant is approximately 12.34 (1.47 to 125.0) times the chance of patients with asymptomatic disease, with a $p$ value of 0.05 .

\section{DISCUSSION}

This study sought to describe the clinical characteristics, risk factors and the association with carotid stenosis in a sample of patients with symptomatic peripheral arterial disease treated by a reference service in Angiology and Vascular Surgery.

This is an unprecedented work in Brazil, since similar studies have not been found after research conducted in the SciELO and LILACS databases. The study of carotid artery disease and peripheral arterial disease are topics of great relevance, since stroke is currently the leading cause of death in Brazil and peripheral arterial disease is responsible for thousands of amputations ${ }^{3-5}$.

Our results show a $84 \%$ prevalence of carotid stenosis in the sample, being significant in $40 \%$ of patients. Previous studies reported a prevalence of significant carotid stenosis ranging from $14.3 \%$ to $37.2 \%$, but the samples of patients with peripheral arterial disease are different between the works, and in many of them there are only asymptomatic and claudicating patients 8,9,19,20. The higher

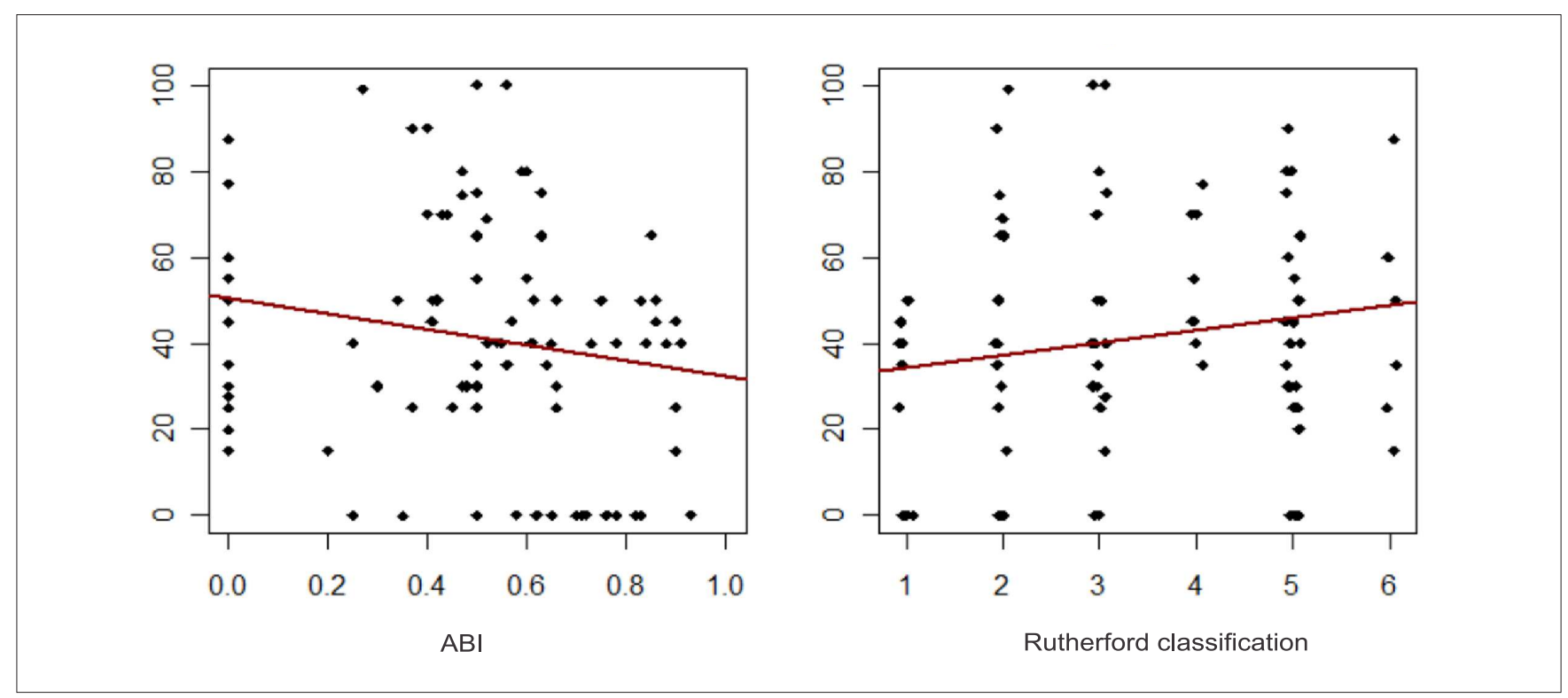

Figure 2 - Scatter Plot of the ankle-brachial index (ABI) and the Rutherford classification according to the degree of carotid stenosis. 
Table 3 - Descriptive measures and Mann-Whitney test for carotid stenosis and the variables studied.

\begin{tabular}{|c|c|c|c|c|c|c|}
\hline Variables & & $\mathrm{N}$ & 1st Q & 2nd $Q$ & 3rd Q & $p$ value \\
\hline \multirow[t]{2}{*}{ Gender } & Female & 39 & 7.5 & 45.0 & 65.0 & 0.8508 \\
\hline & Male & 61 & 25.0 & 40.0 & 50.0 & \\
\hline \multirow[t]{2}{*}{ Motor activity } & Normal & 81 & 25.0 & 40.0 & 55.0 & 0.1931 \\
\hline & Reduced & 19 & 30.0 & 50.0 & 60.0 & \\
\hline \multirow[t]{2}{*}{ Exposure to smoke } & No & 34 & 30.0 & 45.0 & 55.0 & 0.3515 \\
\hline & Yes & 66 & 25.0 & 35.0 & 60.0 & \\
\hline \multirow[t]{2}{*}{ Systemic hypertension } & No & 14 & 0.0 & 35.0 & 50.0 & 0.3185 \\
\hline & Yes & 86 & 25.0 & 40.0 & 60.0 & \\
\hline \multirow[t]{2}{*}{ Age } & $£ 70$ & 47 & 25.0 & 35.0 & 50.0 & 0.1819 \\
\hline & $>70$ & 53 & 30.0 & 45.0 & 60.0 & \\
\hline \multirow[t]{2}{*}{ Diabetes } & No & 53 & 25.0 & 40.0 & 55.0 & 0.2887 \\
\hline & Yes & 47 & 25.0 & 45.0 & 58.5 & \\
\hline \multirow[t]{2}{*}{ Dyslipidemia } & No & 35 & 7.5 & 30.0 & 50.0 & 0.0497 \\
\hline & Yes & 65 & 25.0 & 40.0 & 60.0 & \\
\hline \multirow[t]{2}{*}{ Coronary heart disease } & No & 76 & 25.0 & 40.0 & 55.0 & 0.1920 \\
\hline & Yes & 24 & 28.8 & 50.0 & 60.0 & \\
\hline \multirow[t]{2}{*}{ Renal insufficiency } & No & 84 & 25.0 & 40.0 & 55.0 & 0.1710 \\
\hline & Yes & 16 & 27.5 & 47.5 & 77.3 & \\
\hline \multirow[t]{2}{*}{ Positive family history } & No & 40 & 26.3 & 40.0 & 57.5 & 1.0000 \\
\hline & Yes & 60 & 25.0 & 40.0 & 58.5 & \\
\hline \multirow[t]{2}{*}{ Prior history of vascular surgery } & No & 52 & 22.5 & 40.0 & 57.5 & 0.6802 \\
\hline & Yes & 48 & 26.3 & 40.0 & 61.0 & \\
\hline \multirow[t]{2}{*}{ Prior cerebrovascular disease - symptomatic } & Yes & 7 & 55.0 & 75.0 & 85.0 & 0.0050 \\
\hline & No & 93 & 25.0 & 40.0 & 55.0 & \\
\hline \multirow[t]{2}{*}{ Infrapopliteal } & No & 57 & 25.0 & 40.0 & 65.0 & 0.7851 \\
\hline & Yes & 43 & 25.0 & 40.0 & 50.0 & \\
\hline \multirow[t]{2}{*}{ Femoropopliteal } & No & 37 & 20.0 & 40.0 & 55.0 & 0.4303 \\
\hline & Yes & 63 & 26.3 & 40.0 & 60.0 & \\
\hline \multirow[t]{2}{*}{ Aortoiliac } & No & 74 & 25.0 & 40.0 & 55.0 & 0.6275 \\
\hline & Yes & 26 & 25.0 & 40.0 & 65.0 & \\
\hline \multirow[t]{2}{*}{ Conduct in PAD: surgery } & No & 41 & 30.0 & 40.0 & 50.0 & 0.7622 \\
\hline & Yes & 59 & 25.0 & 40.0 & 58.5 & \\
\hline
\end{tabular}

${ }^{1{ }^{s t} Q} \mathrm{Q}$ : first quartile; $2^{\text {nd }} Q$ : second quartile (median); $3^{\text {rd }} Q$ : third quartile; $P A D$ : peripheral arterial disease.

prevalence of carotid stenosis found in our sample can be explained by the severity of the patients' peripheral arterial disease, since half of the them had critical ischemia of the lower limbs, indicating greater arterial involvement.

As for the studied risk factors for atherosclerosis, the results are consistent with published data, indicating an association with hypertension, smoking, diabetes, dyslipidemia, coronary artery disease, positive family history and chronic renal failure ${ }^{2}$. Dyslipidemia was statistically significant for the presence of carotid stenosis in univariate analysis ( $p=0.0497$ ). None of these factors, however, was statistically significant for the severity of carotid stenosis after multivariate analysis and logistic regression. This may be explained by the fact that both factors have a high prevalence both in patients with peripheral arterial disease and in patients with carotid stenosis, indicating that these are potential markers of systemic atherosclerosis. The identification of modifiable risk factors configures an important part of treatment. In all study patients, once risk factors and associated comorbidities were identified, medical therapy was initiated. The use of antiplatelet agents, statins, smoking cessation and controlling blood pressure and diabetes are essential to prevent stroke ${ }^{21}$.

The average age of patients was 69.78 years, also indicating a direct relationship of arterial involvement with the elder population, in accordance to previously published work ${ }^{22}$. Distribution by age groups also revealed a predominance of older patients, with $80 \%$ of individuals in the series with greater than or equal to 60 years of age.

There was a predominance of male patients in our study, the proportion of about three men to two women, also compatible with the publications found in the literature, in which it is evident that atherosclerosis predominates in males ${ }^{2}$. Our results show, however, an interesting finding after multivariate analysis logistic regression. The females showed a trend $(p=0.0759)$ for significant carotid stenosis. 
Table 4 - Distribution of patients into two groups according to the degree of carotid stenosis and the variables studied.

\begin{tabular}{|c|c|c|c|c|c|c|c|}
\hline \multirow[t]{2}{*}{ Potential predictors } & & \multicolumn{2}{|c|}{ Degree of stenosis } & \multirow[b]{2}{*}{$p$ value } & \multirow[b]{2}{*}{ Odds ratio } & \multicolumn{2}{|c|}{ I.C. $-95 \%$} \\
\hline & & $<50$ & $>50$ & & & IL & SL \\
\hline \multirow[t]{2}{*}{ Gender } & Male & 40 & 21 & 0.155 & 1.00 & - & - \\
\hline & Female & 20 & 19 & & 1.80 & 0.797 & 4.111 \\
\hline \multirow[t]{2}{*}{ Motor activity } & Normal & 52 & 29 & 0.077 & 1.00 & - & \\
\hline & Reduced & 8 & 11 & & 2.47 & 0.891 & 6.822 \\
\hline \multirow[t]{2}{*}{ Exposure to smoke } & No & 19 & 15 & 0.546 & 1.00 & - & \\
\hline & Yes & 41 & 25 & & 0.77 & 0.333 & 1.789 \\
\hline \multirow{2}{*}{ Hypertension } & No & 10 & 4 & 0.347 & 1.00 & - & - \\
\hline & Yes & 50 & 36 & & 1.80 & 0.523 & 6.196 \\
\hline \multirow[t]{2}{*}{ Age } & $<70$ & 31 & 16 & 0.252 & 1.00 & - & - \\
\hline & $>70$ & 29 & 24 & & 1.60 & 0.713 & 3.605 \\
\hline \multirow[t]{2}{*}{ Diabetes } & No & 35 & 18 & 0.191 & 1.00 & - & - \\
\hline & Yes & 25 & 22 & & 1.71 & 0.763 & 3.835 \\
\hline \multirow[t]{2}{*}{ Dyslipidemia } & No & 24 & 11 & 0.199 & 1.00 & - & - \\
\hline & Yes & 36 & 29 & & 1.76 & 0.74 & 4.175 \\
\hline \multirow[t]{2}{*}{ Coronary heart disease } & No & 49 & 27 & 0.104 & 1.00 & - & - \\
\hline & Yes & 11 & 13 & & 2.15 & 0.846 & 5.437 \\
\hline \multirow[t]{2}{*}{ Renal insufficiency } & No & 52 & 32 & 0.413 & 1.00 & - & - \\
\hline & Yes & 8 & 8 & & 1.40 & 0.567 & 4.6 \\
\hline \multirow[t]{2}{*}{ Positive family history } & No & 24 & 16 & 1.000 & 1.00 & - & - \\
\hline & Yes & 36 & 24 & & 1.00 & 0.442 & 2.263 \\
\hline \multirow[t]{2}{*}{ Prior history of vascular surgery } & No & 31 & 21 & 0.935 & 1.00 & - & - \\
\hline & Yes & 29 & 19 & & 0.97 & 0.434 & 2.154 \\
\hline \multirow[t]{2}{*}{ Prior cerebrovascular disease } & Asymptomatic & $=59$ & 34 & 0.016 & 1.00 & - & \\
\hline & Symptomatic & 1 & 6 & & 12.34 & 1.21 & 45.45 \\
\hline \multirow[t]{2}{*}{ Amputation } & No & 59 & 38 & 0.562 & 1.00 & - & \\
\hline & Yes & 1 & 2 & & 1.51 & 0.327 & 20.299 \\
\hline \multirow[t]{2}{*}{ Infrapopliteal } & No & 34 & 23 & 0.934 & 1.00 & - & - \\
\hline & Yes & 26 & 17 & & 0.97 & 0.431 & 2.17 \\
\hline \multirow[t]{2}{*}{ Femoropopliteal } & No & 23 & 14 & 0.735 & 1.00 & - & - \\
\hline & Yes & 37 & 26 & & 1.15 & 0.502 & 2.654 \\
\hline \multirow[t]{2}{*}{ Aortoiliac } & No & 45 & 29 & 0.780 & 1.00 & - & - \\
\hline & Yes & 15 & 11 & & 1.14 & 0.459 & 2.819 \\
\hline \multirow[t]{2}{*}{ Conduct in PAD: surgery } & No & 26 & 15 & 0.561 & 1.00 & - & - \\
\hline & Yes & 34 & 25 & & 1.28 & 0.562 & 2.89 \\
\hline
\end{tabular}

IL: inferior limit; SL: superior limit. PAD: peripheral arterial disease.

A previous publication has shown the female gender as a risk factor for the progression of carotid stenosis in patients with peripheral arterial disease ${ }^{9}$. Other studies have shown that the female sex is also an independent risk factor for significant carotid stenosis, but in a population of coronary patients in preoperative of surgical myocardial revascularization ${ }^{23}$. The female gender appears to be a risk factor for neurological complications after carotid angioplasty and restenosis after carotid endarterectomy ${ }^{24-26}$.

The study of the variables ankle-brachial index $(\mathrm{ABI})$ and classification of Rutherford showed a relationship between severity of peripheral artery disease and severity of carotid stenosis. Despite the non-significant values found in the statistical analysis, there was a tendency towards lower measures of $A B I$ and higher values in the classification of Rutherford, featuring a more severe peripheral arterial disease, and findings of more pronounced carotid stenosis. These findings are consistent with published data indicating that there is direct association between the severity of peripheral arterial disease and degree of carotid stenosis 19,27.

Patients were studied regarding the arterial territory of the affected lower limb. There was a predominance of the femoropopliteal segment, almost two thirds of patients, followed by the aortoiliac and infrapopliteal 
territory. However, there was no statistically significant relationship between these variables and the involvement of the carotid arteries.

An important point to be emphasized concerns the approach to the patient after the duplex scan examination of the carotid. There was change in the conduct, which initially would be expectant without the prior diagnosis of carotid stenosis, in $24 \%$ of the patients. In these, the finding of stenosis was considered so relevant as to requested a more detailed study of the degree of stenosis. In $15 \%$ of patients, only additional exams were performed, without intervention. In 9\%, carotid intervention was held according to the indication criteria established in large randomized studies $10,15,17,28$. These intervention patients showed carotid stenosis greater than $70 \%$, and were indicated a treatment with level 1 scientific evidence for prevention of cerebrovascular accident. It should be noted that the required number of patients to be operated to prevent a single stroke accident in five years is high, about six endarterectomies in symptomatic patients and 17 in asymptomatic ones 29,30 in services with low rates of postoperative neurological complications. Even for the non-operated patients we initiated the appropriate clinical treatment, currently considered the first option for treatment of asymptomatic patients by some authors ${ }^{21}$. Both the diagnosis and the indicated treatment would not have been carried if the examination of the carotid arteries was not requested. Early diagnosis and treatment of carotid stenosis are of utmost importance for the prevention of stroke, as already emphasized ${ }^{11}$

The presence of prior neurological symptoms related to the carotid territory was also statistically significant for the presence of carotid stenosis after logistic regression and multivariate analysis. It should be emphasized, however, that the patients in this sample classified as having a history of neurological symptoms had presented with these at least more than two years before, ie, they had no recent history of neurological symptoms, which might not motivate the request of a carotid echo-color-doppler study. In the NASCET study ${ }^{30}$ patients were considered symptomatic only if they had neurological symptoms in the carotid territory in the past six months.

Patients with symptomatic peripheral arterial disease display a high prevalence of significant carotid stenosis (40\%). There was a trend in the association between severity of peripheral artery disease and severity of carotid stenosis, although not significant. Previous history of neurological symptoms was statistically significant in explaining the severity of carotid stenosis. In conclusion, the study of the carotid arteries by duplex scan examination is of paramount importance in the evaluation of patients with symptomatic peripheral arterial disease and should be systematically indicated to such patients.

\title{
R E S U M O
}

\begin{abstract}
Objetivo: estudar estenose das artérias carótidas nos pacientes com doença arterial periférica sintomática. Métodos: avaliaramse consecutivamente 100 portadores de doença arterial periférica sintomática, nos estágios de claudicação intermitente, dor em repouso ou lesão trófica. A estenose carotídea foi estudada pelo eco-color-doppler, sendo considerada significativa quando maior ou igual a 50\%. A análise univariada foi utilizada para selecionar os potenciais preditores de estenose carotídea, levados posteriormente para análise multivariada. Resultados: a prevalência de estenose carotídea foi $84 \%$, sendo significativa em $40 \%$ e acentuada em 17\%. A idade variou de 43 a 89 anos (média de 69,78). Quanto ao sexo, 61\% foram do sexo masculino e 39\% do feminino. Metade dos pacientes da amostra era claudicante e metade tinha isquemia crítica. Quanto aos fatores de risco, $86 \%$ dos pacientes apresentaram hipertensão arterial sistêmica, 66\% exposição ao fumo, 47\% diabetes, 65\% dislipidemia, 24\% coronariopatia, 16\% insuficiência renal e 60\% história familiar positiva para doenças cardiovasculares. Em sete pacientes, havia história de alguma sintomatologia cérebro-vascular isquêmica no território carotídeo. A presença de sintomatologia cérebro-vascular mostrou-se estatisticamente significativa para influenciar o grau de estenose nas artérias carótidas ( $p=0,02$ na avaliação global e p=0,05 nos subgrupos de estenoses significativas e não significativas). Conclusão: o estudo das artérias carótidas através do exame de duplexscan é de suma importância na avaliação dos pacientes portadores de doença arterial periférica sintomática, devendo-se realizar o estudo de forma sistemática nos pacientes.
\end{abstract}

Descritores: Artérias carótidas. Estenose das carótidas. Doença arterial periférica. Fatores de risco.

\section{REFERENCES}

1. Jotkowitz $A B$, Mark Clarfield A, Faust G, Wartman SA. Screening for carotid artery disease in the general public. Eur J Intern Med. 2005;16(1):34-6

2. Alzamora MT, Forés R, Baena-Díez JM, Pera G, Toran P, Sorribes $M$, et al. The peripheral arterial disease study (PERART/ARTPER): prevalence and risk factors in the general population. BMC Public Health. 2010;10:38.
3. Lotufo PA, Goulart AC, Fernandes TG, Benseñor IM. A reappraisal of stroke mortality trends in Brazil (1979-2009). Int J Stroke. 2013;8(3):155-63.

4. Goulart AC, Bustos IR, Abe IM, Pereira AC, Fedeli LM, Benseñor $I M$, et al. A stepwise approach to stroke surveillance in Brazil: the EMMA (Estudo de Mortalidade e Morbidade do Acidente Vascular Cerebral) study. Int J Stroke. 2010;5(4):284-9.

5. Lotufo PA, Benseñor IM. Stroke mortality in Brazil: one example of delayed epidemiological cardiovascular transition. Int J Stroke. 2009;4(1):40-1 
6. Brasil. Ministério da Saúde. DATASUS. Sistema de Informações Hospitalares do SUS (SIH/SUS). Disponível em: http:// www2.datasus.gov.br/DATASUS/index.php.

7. Ankle Brachial Index Collaboration, Fowkes FG, Murray GD, Butcher I, Heald CL, Lee RJ, et al. Ankle brachial index combined with Framingham Risk Score to predict cardiovascular events and mortality: a meta-analysis. JAMA. 2008;300(2):197-208.

8. Brevetti G, Sirico G, Lanero S, De Maio JI, Laurenzano E, Giugliano $\mathrm{G}$. The prevalence of hypoechoic carotid plaques is greater in peripheral than in coronary artery disease and is related to the neutrophil count. J Vasc Surg. 2008;47(3):523-9.

9. Jahromi AS, Clase CM, Maggisano R, Bailey R, Safar HA, Cinà CS. Progression of internal carotid artery stenosis in patients with peripheral arterial occlusive disease. J Vasc Surg. 2009;50(2):2928.

10. Jayasooriya G, Thapar A, Shalhoub J, Davies AH. Silent cerebral events in asymptomatic carotid stenosis. J Vasc Surg. 2011;54(1):227-36.

11. Weinberger J. Prevention of ischemic stroke. Curr Cardiol Rep. 2002:4(2):164-71.

12. North American Symptomatic Carotid Endarterectomy Trial Collaborators. Beneficial effect of carotid endarterectomy in symptomatic patients with high-grade carotid stenosis. N Engl J Med. 1991:325(7):445-53.

13. Randomised trial of endarterectomy for recently symptomatic carotid stenosis: final results of the MRC European Carotid Surgery Trial (ECST). Lancet. 1998;351(9113):1379-87.

14. Halliday A, Mansfield A, Marro J, Peto C, Peto R, Potter J, et al. Prevention of disabling and fatal strokes by successful carotid endarterectomy in patients without recent neurological symptoms: randomised controlled trial. Lancet. 2004;363(9420):1491-502.

15. Chambers BR, Donnan GA. Carotid endarterectomy for asymptomatic carotid stenosis. Cochrane Database Syst Rev. 2005(4):CD001923.

16. Endarterectomy for asymtomatic carotid artery stenosis. Executive Committee for the Asymptomatic Carotid Atherosclerosis Study. JAMA. 1995:273:1421-8.

17. Halliday A, Harrison M, Hayter E, Kong X, Mansfield A, Marro J, et al. 10-year stroke prevention after successful carotid endarterectomy for asymptomatic stenosis (ACST-1): a multicentre randomised trial. Lancet. 2010;376(9746):1074-84.

18. Grant EG, Benson CB, Moneta GL, Alexandrov AV, Baker JD, Bluth El, et al. Carotid artery stenosis: gray-scale and Doppler US diagnosis-Society of Radiologists in Ultrasound Consensus Conference. Radiology. 2003;229(2):340-6.

19. Goessens BM, Visseren FL, Algra A, Banga JD, van der Graaf $Y$, SMART Study Group. Screening for asymptomatic cardiovascular disease with noninvasive imaging in patients at high-risk and lowrisk according to the European Guidelines on Cardiovascular Disease
Prevention: the SMART study. J Vasc Surg. 2006;43(3):525-32.

20. Mostaza JM, González-Juanatey JR, Castillo J, Lahoz C, FernándezVillaverde JM, Maestro-Saavedra FJ. Prevalence of carotid stenosis and silent myocardial ischemia in asymptomatic subjects with a low ankle-brachial index. J Vasc Surg. 2009;49(1):104-8.

21. Naylor AR. Time to rethink management strategies in asymptomatic carotid artery disease. Nat Rev Cardiol. 2011;9(2):116-24.

22. Casella IB, Sotelo FJ, Yamazaki Y, Presti C, Vassoler A, Melo HA. Comparison of common carotid artery intima-media thickness between Brazilian Euro-descendants and Afro-descendants with atherosclerosis risk factors. Clinics. 2009;64(7):657-64.

23. Shirani S, Boroumand MA, Abbasi SH, Maghsoodi N, Shakiba M, Karimi A, et al. Preoperative carotid artery screening in patients undergoing coronary artery bypass graft surgery. Arch Med Res. 2006;37(8):987-90.

24. Yun WS, Kwun WH, Suh BY. The early and mid-term results of carotid artery stenting in high-risk patients. J Korean Surg Soc. 2011;80(4):283-8

25. Micari A, Stabile E, Cremonesi A, Vadalà G, Castriota F, Pernice V, et al. Carotid artery stenting in octogenarians using a proximal endovascular occlusion cerebral protection device: a multicenter registry. Catheter Cardiovasc Interv. 2010;76(1):9-15.

26. Crawford RS, Chung TK, Hodgman T, Pedraza JD, Corey M, Cambria RP. Restenosis after eversion vs patch closure carotid endarterectomy. J Vasc Surg. 2007;46(1):41-8.

27. Busch MA, Lutz K, Röhl JE, Neuner B, Masuhr F. Low ankle-brachial index predicts cardiovascular risk after acute ischemic stroke or transient ischemic attack. Stroke. 2009;40(12):3700-5.

28. Liapis CD, Bell PR, Mikhailidis D, Sivenius J, Nicolaides A, Fernandes e Fernandes J, et al. ESVS guidelines. Invasive treatment for carotid stenosis: indications, techniques. Eur J Vasc Endovasc Surg. 2009;37(4 Suppl):1-19.

29. Rothwell PM, Eliasziw M, Gutnikov SA, Warlow CP, Barnett HJ; Carotid Endarterectomy Trialists Collaboration. Endarterectomy for symptomatic carotid stenosis in relation to clinical subgroups and timing of surgery. Lancet. 2004;363(9413):915-24.

30. Inzitari D, Eliasziw M, Gates P, Sharpe BL, Chan RK, Meldrum HE, et al. The causes and risk of stroke in patients with asymptomatic internal-carotid-artery stenosis. North American Symptomatic Carotid Endarterectomy Trial Collaborators. N Engl J Med. 2000;342(23):1693-700

Received on 15/10/2013

Accepted for publication 09/01/2014

Conflict of interest: none.

Source of funding: none.

Mailing address:

Leonardo Ghizoni Bez

E-mail:Igbez@terra.com.br 